\title{
Manejo postsacrificial del cuerpo humano: evidencias e implicaciones rituales en un entierro del Clásico Terminal en Lagartero, Chiapas
}

\section{Postsacrificial Management of Human Body: Evidence and Ritual Implications of a Terminal Classic Burial in Lagartero, Chiapas}

\author{
Judith L. Ruiz GonZÁLEZ \\ Posgrado en Estudios Mesoamericanos, UNAM \\ Carlos Serrano Sánchez \\ Instituto de Investigaciones Antropológicas, UNAM \\ Sonia Rivero ToRres \\ Dirección de Estudios Arqueológicos, INAH
}

\begin{abstract}
Resumen: La investigación de los restos óseos humanos de un contexto arqueológico del período Clásico, en el sitio de Lagartero, Chiapas, reveló que se trata de segmentos anatómicos incompletos de un individuo masculino, con marcas antropogénicas peri mortem y post mortem distribuidas en varias áreas de los huesos. Con base en la evidencia antropológica en combinación con el hecho de que el esqueleto se asocia a uno de los altares del juego de pelota, consideramos que se trata de los restos de una víctima sacrificada. El cadáver también había sido procesado post mortem, probablemente con fines rituales o para fabricar artefactos de hueso.
\end{abstract}

Palabras clave: arqueología, osteología, marcas antropogénicas, sacrificio humano, rituales post mortem.

AвSTRACT: The investigation of human remains from a Classic period deposit at the archaeological site of Lagartero revealed incomplete anatomical segments of a male individual with anthropogenic perimortem and postmortem marks distributed in various areas of the bones. Based on the anthropological evidence in combination with the fact that the skeleton comes from one of the ball court altars, we assume that these are the remains of a sacrificed victim. The corpse also had been heavily processed postmortem, probably for ritual purposes or to be manufactured into bone artifacts.

KEYwords: archeology, osteology, anthropogenic marks, human sacrifice, postmortem rituals.

RECEPCIÓN:: 8 de abril de 2015.

ACEPTACIÓN: 11 de octubre de 2015.

DOI: 10.19130/iifl.ecm.2016.48.757 


\section{Introducción}

El presente trabajo aborda el estudio de un depósito de restos óseos de carácter no funerario, asociado a un altar del juego de pelota en la zona arqueológica de Lagartero, Chiapas, localizado durante las exploraciones llevadas a cabo en 2011. Los restos esqueléticos reflejaron un procesamiento peri mortem y post mortem, que implican sacrificio humano. ${ }^{1}$

En el contexto arqueológico se encontraron segmentos anatómicos en estado articulado, correspondientes a un mismo individuo. El análisis osteológico indicó que los restos pertenecían a un hombre adulto joven. A través de diversas marcas antropogénicas presentes en las regiones cervical y torácica, así como en las superficies articulares y de inserciones musculares, planteamos la posibilidad de que el individuo fuese sacrificado y procesado post mortem para su aprovechamiento póstumo y que, finalmente, el cuerpo fue depositado en el muro posterior del altar sureste del juego de pelota. Es posible que los restos fungieran como vivificadores para que una construcción siguiera en pie, dado que los huesos, de acuerdo a la cosmovisión prehispánica, guardan parte de la fuerza vital del individuo, aún después de muerto.

En este estudio se llega a la conclusión de que, después de la inmolación del individuo, el cuerpo fue dispuesto tanto para fines rituales como para el aprovechamiento funcional de algunos segmentos anatómicos, dado que desde épocas muy remotas el hueso humano ha sido un elemento útil y significativo para la elaboración de instrumentos. ${ }^{2}$

\section{El sitio arqueológico de Lagartero}

Lagartero se localiza en el sureste de México, en el estado de Chiapas, dentro del municipio de La Trinitaria, próximo a la frontera con Guatemala; el asentamiento se ubica en una planicie que se extiende hasta los Cuchumatanes guatemaltecos (Mapa 1).

\footnotetext{
${ }^{1}$ El entierro primario es aquel que presenta los elementos óseos en relación anatómica, incluyendo inhumaciones de uno o varios segmentos de un cadáver. También puede ser individual o colectivo. El secundario es el que no muestra relación anatómica de sus partes; puede ser el caso de entierros primarios removidos para reuso del espacio o ser transportados a otro sitio, quedando agrupados de manera irregular. Estos criterios se basan en el modelo de sistema de enterramiento propuesto por Romano (1974: 88) para el México antiguo.

2 Está práctica del tratamiento del cadáver y su aprovechamiento se puede encontrar en otros contextos culturales mesoamericanos. Por ejemplo, en Mayapán hay evidencia ósea de desmembramiento, descarnamiento, posible antropofagia y producción de artefactos a partir de huesos humanos (Serafin y Peraza, 2007: 241-244). En Teotihuacan se sabe que las personas disponían de los restos de sus muertos de diferentes maneras, como transformar los huesos de los difuntos en artefactos que servían en la vida cotidiana, social y simbólica (Meza, 2015: 134-139). Otro caso es el de Oaxaca, con la manufactura de reliquias a partir de restos óseos: cabezas-trofeo, pectorales de maxilares, raspadores de fémures, mandíbulas y cráneos grabados (Urcid, 2010: 129, 138, 140).
} 


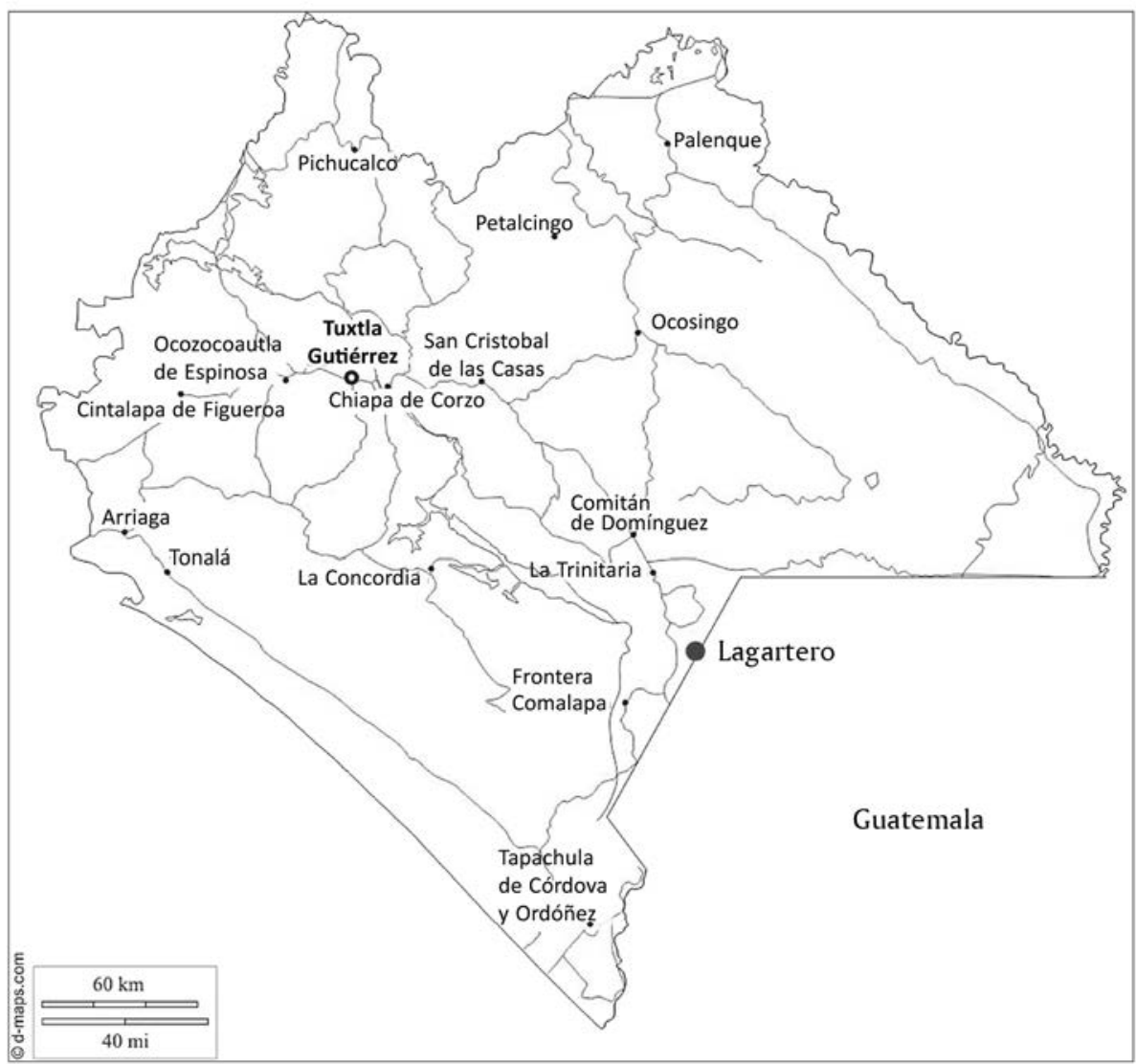

MAPA 1. Ubicación de Lagartero. Tomado de < tile://C:/Users/Dell/Documents/2015/Publicaciones\%20 y\%20congresos\%202015/Lagartero,\%20RECM/mapa\%201.gif> y modificado.

El sitio arqueológico recibió este nombre por la ciénega de Lagartero, que es alimentada por manantiales locales y los ríos de Lagartero y San Lucas, afluentes superiores del río Grijalva, que corren de este a oeste. El sitio constituye una región lacustre y húmeda, situada sobre estratos marinos del Mesozoico Superior y el Terciario Inferior Medio. El subsuelo está formado por rocas calizas con terrenos cársticos de relieve variado: agujeros, dolinas y hendiduras en forma de cráteres, que dieron lugar a los Lagos de Colón (Rivero, 2007: 184). El sitio está rodeado por una vegetación baja de selva tropical, debido a su localización geográfica y al clima de la región de tierra caliente. Gran parte de él está localizado en pequeñas islas y penínsulas que se proyectan dentro de lagos.

Lagartero fue un gran centro cívico-religioso, cuyo núcleo ceremonial se encuentra en una de las islas más grandes: El Limonal (Limonar), en la parte sur de la ciénega; posiblemente fue un centro rector de la región durante el Clásico Tardío. De acuerdo con los hallazgos arqueológicos, fue habitado principalmente desde el 
Clásico Tardío, 750 a 900 d.C., al Posclásico Temprano, 900 a 1200 d.C., por gente que habló una lengua de la rama del grupo mayense (Kaufman, 1974: 85).

Desde 1974 Thomas Lee ya había reconocido el sitio. En años posteriores Susanna Ekholm realizó varias excavaciones; fue hasta 1990 que se dio inicio al Proyecto Arqueológico de Lagartero-INAH, ${ }^{3}$ bajo la coordinación de la arqueóloga Sonia Rivero Torres, quien ha centrado su labor arqueológica en El Limonar, el área ceremonial (Figura 1).

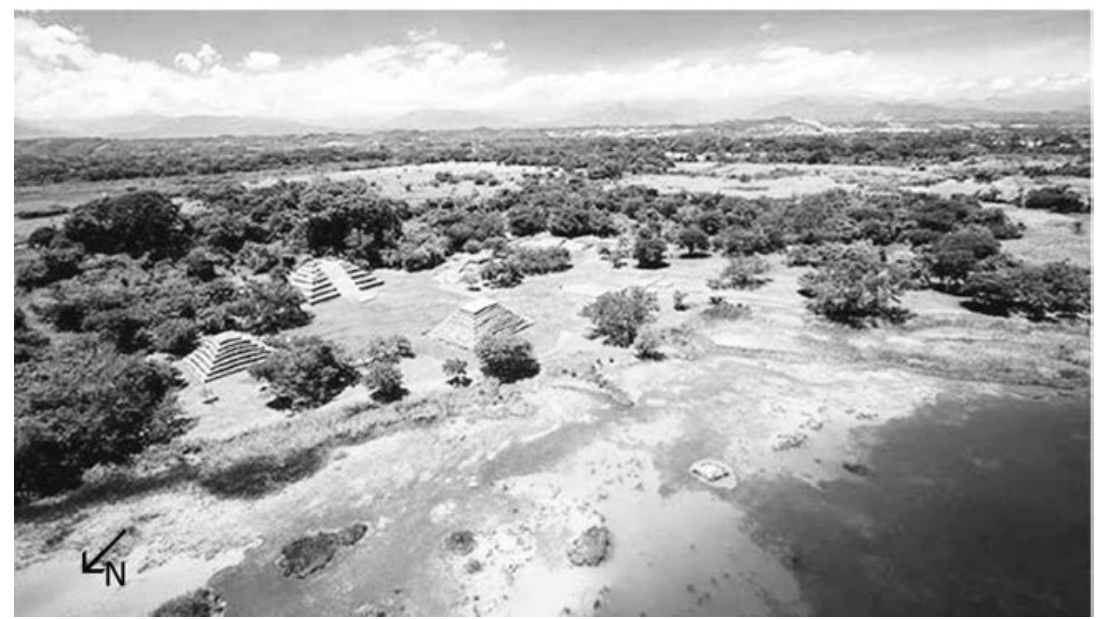

Figura 1. Isla El Limonar, donde se ubica el centro cívico-religioso. Fuente: $<$ https://www.zonaturistica.com/atractivos-turisticos-en/65/la-trinitaria-chiapas.html>.

En este islote se encuentra el mayor número de estructuras definidas, como la acrópolis, el juego de pelota y la plaza principal, limitada ésta última por cuatro pirámides de diferentes tamaños.

El juego de pelota se localiza al sur de la Pirámide número 1. Afuera del juego de pelota y cercanos al muro del lado sur, de este a oeste, hay cinco altares, uno de ellos fue nombrado como la estructura sureste (SE), espacio donde se llevó a cabo el hallazgo (Plano 1).

\section{Descripción del hallazgo}

En los primeros niveles del proceso de excavación del sitio de enterramiento, se hallaron fragmentos de material lítico y cerámico. A partir del cuarto nivel, a lo largo de los perfiles norte, oeste y sur de la estructura, se localizaron restos óseos de animal, concentrándose mayoritariamente en el lado oeste del muro; también se encontraron caracoles, fragmentos de estuco y dos ollas, una de ellas contiene un esqueleto infantil.

\footnotetext{
${ }^{3}$ Instituto Nacional de Antropología e Historia.
} 


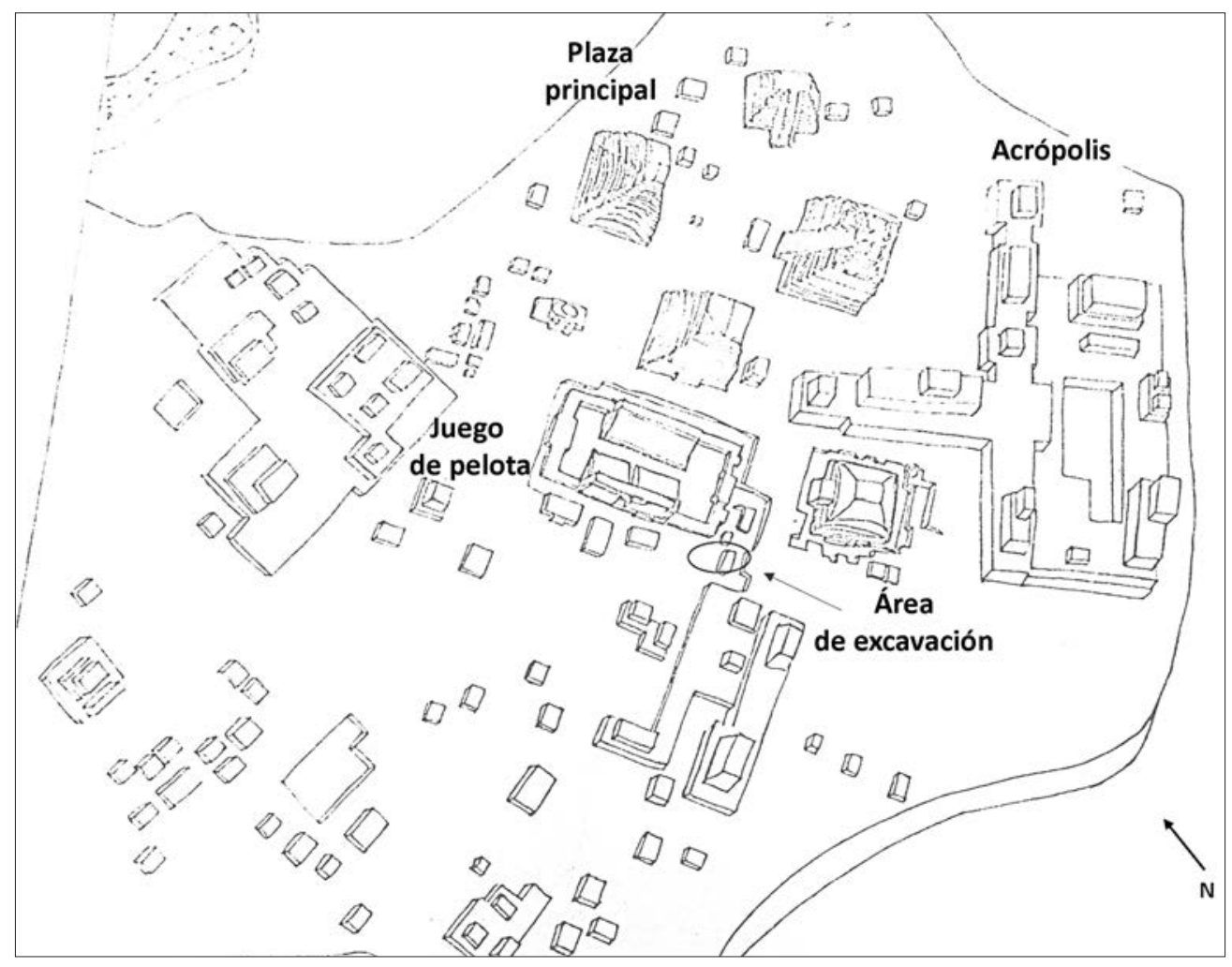

Plano 1. Croquis de la zona arqueológica de Lagartero y ubicación del área de excavación.

Dibujo de Juan Yadeun Angulo. ${ }^{4}$

Cabe mencionar el hallazgo de una osamenta dentro de un contexto ritual, ${ }^{5}$ clasificado como entierro primario, individual e incompleto, localizado en el

4 Aportamos los elementos que tenemos a nuestra disposición para contextualizar el hallazgo arqueológico del entierro estudiado.

${ }^{5}$ Un contexto ritual es aquel en el que son evidentes posiciones irregulares o sugerencias de ataduras; la presencia de entierros simultáneos o múltiples ocurridos en un mismo tiempo, caracterizados por un perfil de sexo y edad no demográfico; o por la ausencia de objetos funerarios asociados (Tiesler y Cucina, 2010: 196). Houston y Scherer (2010: 177-179) y otros autores (Pijoan y Mansilla, 2004: 70; Duncan, 2011: 550) hacen la distinción entre lo funerario y lo ritual con base en evidencias antropogénicas que reflejan la variedad del procesamiento peri mortem y post mortem, así como la eliminación de los desechos del cadáver.

Tales huellas tafonómicas incluyen traumas, fracturas, modificaciones térmicas y marcas de corte localizadas en áreas estratégicas para ocasionar la muerte; estas marcas son muestra evidente de actos sacrificiales. Víctimas de este tipo de muerte, por lo general, son depositadas en lugares rituales o simplemente descartadas. No obstante, existe evidencia de sacrificio humano en contextos funerarios, como son las construcciones mortuorias formales, particularmente tumbas reales. También es posible que la práctica del sacrificio humano no deje huellas antropogénicas a nivel óseo y su clasificación como contexto sacrificial lo proporcione la interpretación del contexto arqueológico (Domenici, 2013: 80-81). 
quinto nivel, cerca del muro oeste de la estructura, que yacía colocado entre dos alineamientos de piedras adosadas, uno hacia el norte y el otro al sur, los cuales surgían del muro oeste. La mayoría de los segmentos óseos depositados unos sobre otros guardaban relación anatómica, a excepción de los ilíacos, sacro, omóplato izquierdo, clavícula izquierda, rótula derecha y epífisis de ambos fémures.

La posición del esqueleto es irregular, con la caja torácica en decúbito ventral orientada de sureste a noroeste (Figura 2).

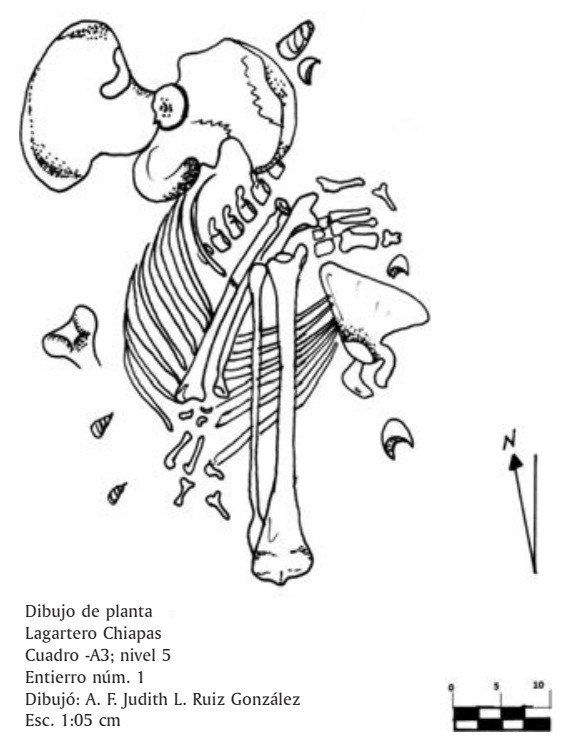

Figura 2. Dibujo de planta del Entierro 1. Dibujo de Judith Ruiz.

Durante el proceso de exploración del entierro se registró, de arriba hacia abajo, la superposición de los huesos en tres niveles de control (Figura 3): (3) antebrazo derecho, pierna derecha (tibia, peroné y huesos de pie), omóplato izquierdo, clavícula izquierda, sacro y ambos ilíacos; (2) después le siguió la caja torácica (costillas y vértebras); y por último (1) antebrazo izquierdo (cúbito, radio y huesos de la mano), rótula derecha y epífisis distales de ambos fémures. No se encontraron objetos asociados directamente al entierro; los fragmentos de cerámica y caracoles (del género Polinices) provienen del relleno de la tierra.

Cabe señalar que en la parte posterior de altar SE del juego de pelota se localizaron dos muros alineados de norte a sur, y entre ellos al individuo referido (Figura 4). Por la ubicación y la manufactura de estos muros adosados, se deduce que funcionaron como una especie de contrafuerte, ya sea preventivo o correctivo, pues el área donde se cimentaron tales montículos es lacustre y el terreno llega a tener oscilaciones que producen perturbaciones en las estructuras. 


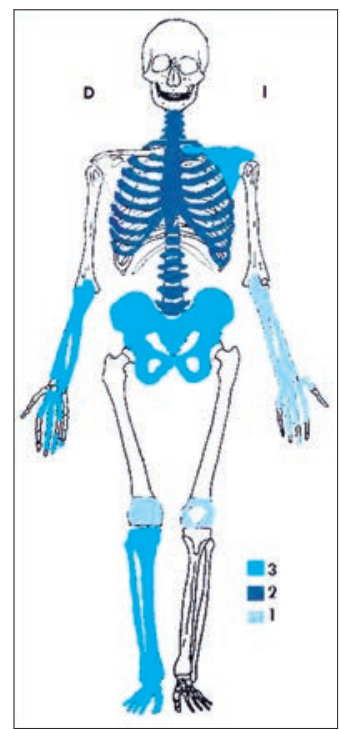

Figura 3. Representación de los huesos hallados en el contexto y la diferenciación según los tres niveles de registro.

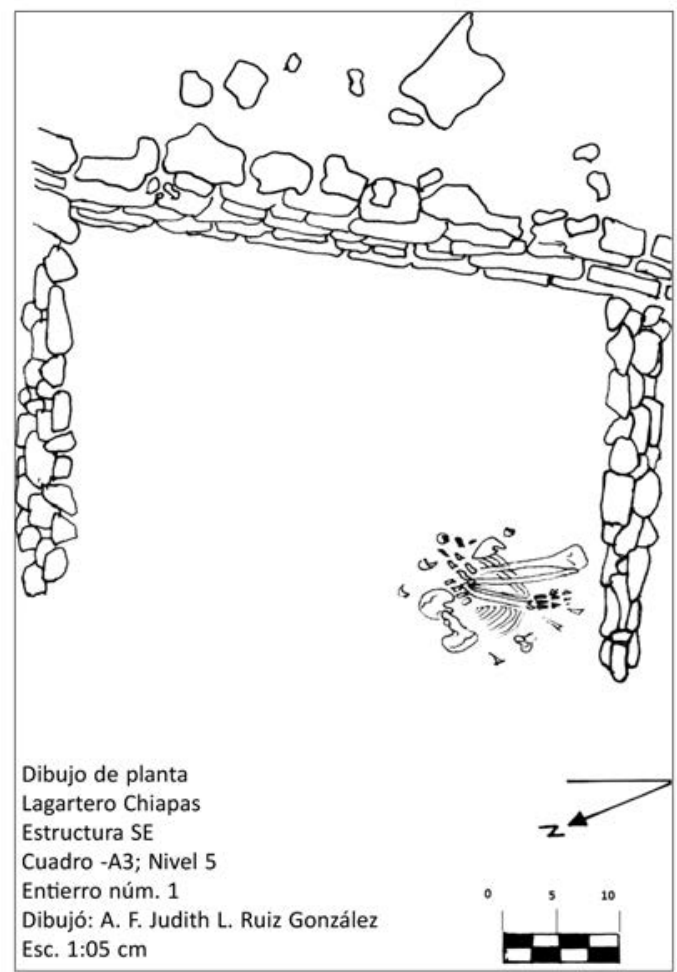

Figura 4. Dibujo en planta de la ubicación del Entierro 1 en la estructura SE. Dibujo de Judith Ruiz. 


\section{Identificación osteológica}

El esqueleto corresponde a un individuo masculino, de acuerdo a la evaluación de la morfología pélvica (Herrmann et al., 1990 en Krenzer, 2006: 11-14; Buikstra y Ubelaker, 1994; Phenice, 1969). Su edad a la muerte fue entre los 22 y 26 años, según los criterios de determinación de la edad consignados por diferentes autores (Ubelaker, 1989; Bass, 1986; Lovejoy et al., 1985; Meindl y Lovejoy, 1989).

Para la estimación de la estatura se utilizó la longitud fisiológica del cúbito izquierdo $(160.88 \mathrm{~cm})$ y del radio izquierdo $(161.0 \mathrm{~cm})$, según las fórmulas de Genovés (1966, en Lagunas y Hernández, 2005: 52).

También cabe mencionar que en el análisis morfoscópico de los segmentos óseos se detectó una lesión en la cara superior de la clavícula izquierda, indicativa del proceso de recuperación de un traumatismo ocurrido ante mortem, así como la presencia de periostitis en tibia, debida a un padecimiento infeccioso no específico, ocasionado por la acción de microorganismos en el transcurso de la vida del individuo.

\section{Tafonomía cultural}

Es evidente la presencia de modificaciones culturales acontecidas en el individuo alrededor de la muerte y posterior a ella. Se encontraron numerosas huellas de corte en la caja torácica, región pélvica, en epífisis de fémur, algunas falanges y metacarpo, con mayor presencia en el lado izquierdo del esqueleto. Las huellas de corte detectadas difieren entre sí por la profundidad y anchura que abarcan en la superficie ósea; esta diferencia se hizo evidente sobre todo en el borde interno de la tibia.

Las regiones con mayor número de huellas de corte son las costillas izquierdas, epífisis distal de fémur izquierdo, clavícula izquierda, tibia derecha e ilíaco derecho; estas marcas predominan en el esqueleto axial (costillas, vértebras y coxales) y se observan en las superficies articulares o de inserciones musculares.

Por la distribución en el área del hueso y de acuerdo al segmento óseo donde se presentan se pueden atribuir a la práctica del sacrificio humano y el tratamiento del cuerpo, finalizando con el depósito de los restos articulados (Cuadro 1).

Dentro de la gran variedad de formas de inmolar a las víctimas según la documentación de las fuentes y del registro osteológico, se encuentra el degollamiento con la posterior decapitación, la evisceración, el ahogamiento, la muerte por flechas, por fuego, el despeñamiento, la extracción cardiaca o de entrañas, el desnucamiento, la inmersión y la lapidación; otra forma era arrojar a la víctima a un volcán (Matos, 2010: 47, 52, 54-56; Tiesler y Cucina, 2010: 199; Nájera, 1987: 110; Rojas Chávez et al., 2004: 102; Houston y Scherer, 2010: 170, 181-184).

Algunas de las técnicas que se empleaban para inmolar a las víctimas pudieron ser lentas y dolorosas, con poco daño al sistema esquelético para su aprovecha- 


\begin{tabular}{|c|c|c|c|c|c|c|}
\hline $\begin{array}{l}\stackrel{\widetilde{U}}{ٍ} \\
\stackrel{\Xi}{0}\end{array}$ & 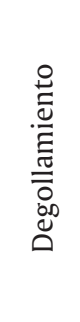 & 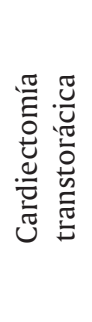 & 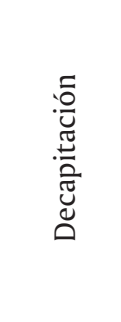 & 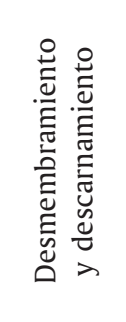 & 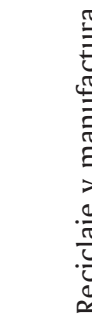 & 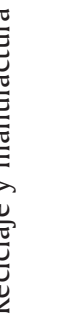 \\
\hline $\begin{array}{l}\frac{0}{N} \\
\stackrel{\Xi}{E}\end{array}$ & 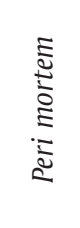 & 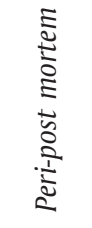 & 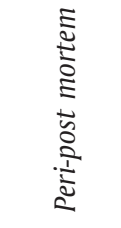 & 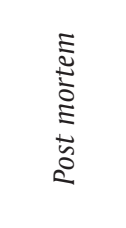 & ta & \\
\hline 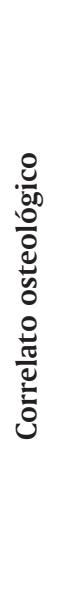 & 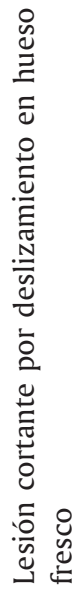 & 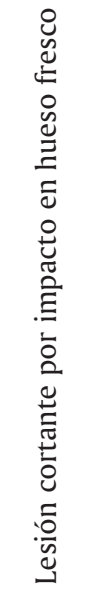 & 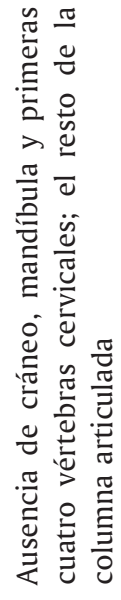 & 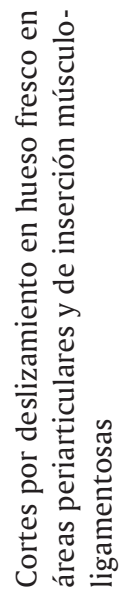 & 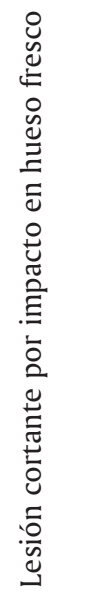 & 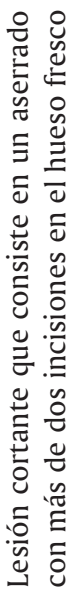 \\
\hline 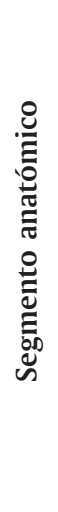 & 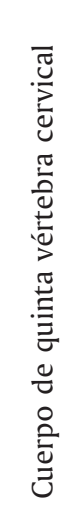 & 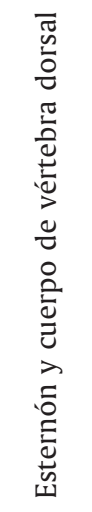 & ' & 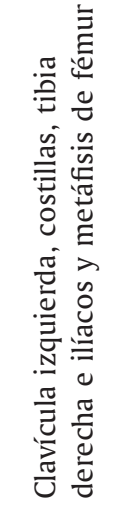 & 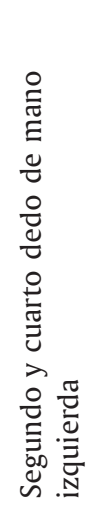 & 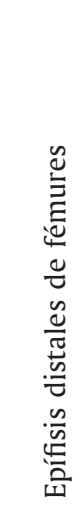 \\
\hline
\end{tabular}


miento post mortem ritual o funcional. Luego de llevar a cabo la occisión ritual, el cuerpo podía ser sometido a una diversidad de procedimientos. Por ejemplo, el cuerpo del sacrificado por cardiectomía era objeto de varias ceremonias como desollamiento, despeñamiento o antropofagia, tal como lo describen Diego de Landa (1966: 55) y Bernardino de Sahagún (1969: 82). En otros casos se separaba la cabeza y se horadaban los temporales para colocarlos en los tzompantlis (Pijoan y Mansilla, 2004: 72; Rojas Chávez et al., ibid., 103). También existe la posibilidad de que el cuerpo fuera simplemente desechado sin ningún rito (Nájera, ibid., 205-206).

\section{La decapitación: la apropiación de la cabeza}

El individuo masculino cuyos restos se estudiaron presenta diversas particularidades, como es la ausencia del cráneo y las primeras cuatro vértebras cervicales; las demás vértebras que conforman la columna fueron halladas en posición anatómica, con respecto a la caja torácica. Se observó la presencia de dos huellas de corte en el cuerpo de la quinta vértebra cervical, probablemente realizado para desangrar y utilizar el líquido vital brotado (Figuras 5 y 6).

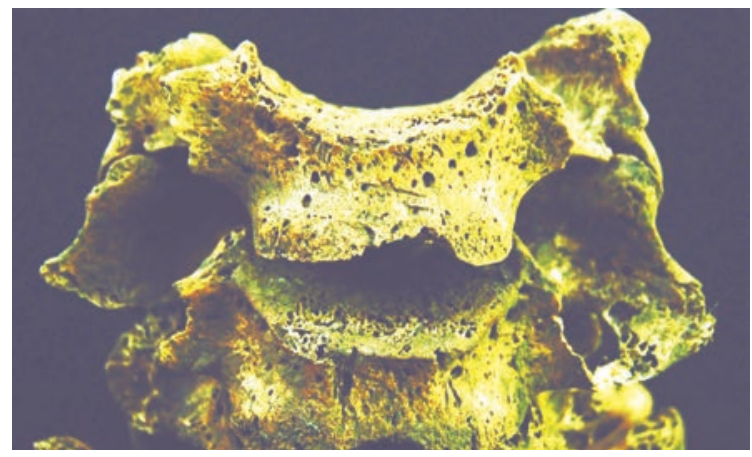

FiguRA 5. Huellas de corte en cuerpo de vértebra cervical. Fotografía de Judith Ruiz.

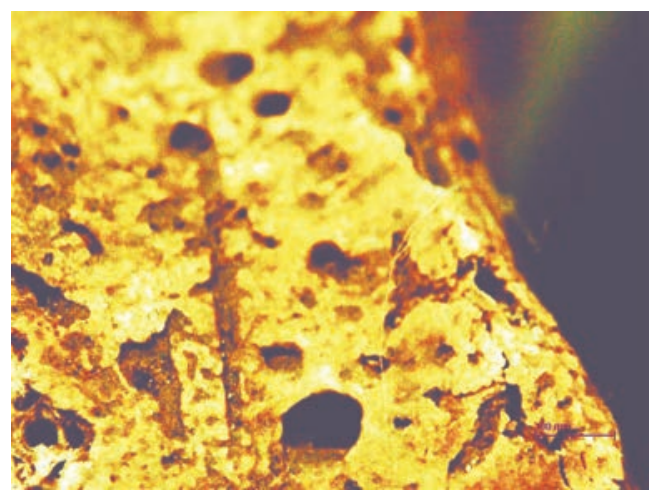

Figura 6. Detalle de huella corte. Fotografía de Judith Ruiz. 
A este acto llevado a acabo peri mortem pudo haber seguido la amputación peri-post mortem de la cabeza, es decir, la decapitación.

En relación al degollamiento/decapitación se han documentado casos en Calakmul, Champotón y Chichén Itzá (Tiesler y Cucina, 2010: 205-207; López Oliva, 2013: 11). Tal decapitación se relaciona con la apropiación de la cabeza, cuya esencia se quiso aprovechar; la entidad anímica que allí se alojaba (b’aahis) era factible de ser adquirida por quien pudiese hacerse con ella poco antes o poco después de la muerte. ${ }^{6}$ Las víctimas podían ser enemigos poderosos, hombres, mujeres y niños; esta acción realizada en beneficio propio o de la comunidad se ha relacionado con los rituales de prestigio, poder, fecundidad, fertilidad y la germinación de nuevos seres o vegetales, e incluso la creación de ciertas construcciones.

La cabeza, como contenedora de una de las entidades anímicas, ${ }^{7}$ era considerada como una semilla germinadora. La naturaleza de esta entidad es fragmentable y adherible de manera parcial a uñas, cabellos y otros lugares o cosas. Las entidades anímicas no sólo residían en lugares específicos (centros anímicos) ${ }^{8}$ como la cabeza o b'aahis y el corazón o o'hlis, más bien tenían la propiedad de difundirse por todo el cuerpo, y hasta salir de él (Martínez, 2007: 155; Velázquez, 2011: 338, 242, 244, 245). Por ejemplo, la sangre era parte de las esencias vitales y alimento para los dioses; los huesos guardaban parte de la energía o fuerza anímica vital del individuo, de ahí la preservación de los adversarios sacrificados o del culto a los ancestros (Tiesler y Cucina, 2010: 205). Lo anterior explica la soltura de apropiarse de un b'aahis ajeno, una vez que el dueño hubiese muerto, a pesar de que el nuevo dueño no fuese su anterior poseedor.

El degollamiento, así como la apropiación de la cabeza, podían darse de manera simultánea; el primero se realizaba con la finalidad de obtener la sangre y ofrendarla a los dioses, y la segunda podía llevarse a cabo para el culto a los ancestros o para la captura de la entidad anímica del enemigo, sin la intención

\footnotetext{
${ }^{6}$ El concepto de la decapitación tiene dos acepciones, de las cuales nos remitiremos sólo a una por no contar con el cráneo y mandíbula. Se refiere a la separación de la cabeza de un cuerpo vivo o muerto, todavía con tejidos blandos, ya sea mediante desarticulación o corte (Chávez, 2010: 319); es decir, la decapitación no implica la forma de muerte, ya que el individuo pudo ser degollado y $a$ posteriori decapitado.

${ }^{7}$ Las entidades anímicas o energía anímica residen en los centros anímicos. Es una unidad estructurada con capacidad de independencia, en ciertas condiciones, al sitio orgánico en el que se ubica, tiene características muy variables: puede ser singular, plural; divisible, indivisible; con funciones específicas, jerarquizables, materiales e inmateriales, separables e inseparables del organismo humano (López Austin, 2012: 197-198). Las fuerzas anímicas son elementos que dotan de vida a la persona sin estar ligadas a las funciones intelectuales; se encuentran vinculadas con fuentes externas que les permiten regenerarse y renovarse durante los ciclos ordinarios de la vida humana, como la respiración y el calor (Velázquez, 2011: 237).

${ }^{8}$ Partes del organismo humano en las que se supone existe una concentración de fuerzas anímicas, de sustancias vitales, y en las que se generan los impulsos básicos de dirección de los procesos que dan vida y movimiento al organismo y permiten la realización de las funciones psíquicas (López Austin, 2012: 197).
} 
de satisfacer a deidades (a excepción de los muros de cráneos denominados tzompantli, entre los nahuas), más bien para el beneficio del captor o de la comunidad entera (López Oliva, 2013: 30, 33, 50, 63). ${ }^{9}$ De acuerdo con Nájera (2003 en López Oliva, 2013: 10) la decapitación en el área maya fue la forma más común de ejecutar el sacrificio humano durante el período Clásico.

\section{La extracción del corazón: esternón cortado}

Según Houston y Scherer (2010: 184), el sacrificio por extracción del corazón entre los mayas de las tierras bajas del sur está escasamente documentado en el registro osteológico; sin embargo, existen datos en Palenque, Calakmul y Becán con la evidencia de huellas de corte sobre costillas y vértebras torácicas (Tiesler y Cucina, 2006: 503). La escasa información bien pudiera deberse al estado de conservación de los restos óseos o a que los enterramientos se llevaran a cabo en contextos funerarios normales, otra posibilidad es que la práctica del sacrificio humano no dejara huellas antropogénicas a nivel óseo y la clasificación como contexto sacrificial lo proporcione la interpretación del contexto arqueológico (Domenici, 2013: 80-84).

En las representaciones iconográficas de la región maya se aprecia que este tipo de occisión ritual se hacía a través de una incisión transversal por debajo de la caja torácica. Entre los mayas peninsulares se ha encontrado evidencia de esternones seccionados por completo, cortados con la finalidad de extraer el corazón a partir de la técnica de cardiectomía (Tiesler y Cucina, 2010: 214). Esta práctica a nivel osteológico se ha identificado así por evidencias que proporcionan los esternones cortados.

El cuerpo del esternón cortado del individuo de Lagartero permite aseverar que se trata de este mismo propósito, llevado a cabo peri-post mortem. La evidencia es apreciable a la altura de la articulación de la sexta costilla; el golpe cortante se realizó en sentido ventro-dorsal, ya que el borde de la cara anterior quedó aplastado y con una rebaba del borde posterior, a consecuencia de la salida del instrumento en esa dirección; dicho corte perjudicó el cuerpo de la novena vertebra dorsal (Figuras 7 y 8 ).

Estas huellas permiten inferir que el corte se hizo desde el espacio intercostal y que se partió el esternón desde la parte exterior hacia la parte interior de la caja torácica. El corte está inclinado hacia abajo de derecha a izquierda, por lo

${ }^{9}$ La decapitación peri mortem no debe tomarse de manera formal como la causa de muerte, ya que al parecer no existían los instrumentos adecuados como para provocar este daño (Alfredo López Austin, Martha I. Nájera, Maricela Ayala y Erik Velásquez, conversación personal 2009-2010 en López Oliva, 2013: 10); si fuera el caso tendría que ser una decapitación por desnucamiento, es decir, uno o más cortes por detrás del cuerpo (Tiesler y Cucina, 2010: 204); es posible que la decapitación fuera una práctica posterior de manera peri mortem o post mortem. Como manejo postsacrificial, la decapitación, ya sea en la fase peri mortem o post mortem (siempre y cuando conserve tejidos blandos), se diferencia de la separación del cráneo post mortem, porque el cuerpo ya está esqueletizado y no deja huellas de corte en vértebras, en este caso ya no se trata de decapitación sino de apropiación del cráneo, no de la cabeza (López Oliva, 2013: 11). 


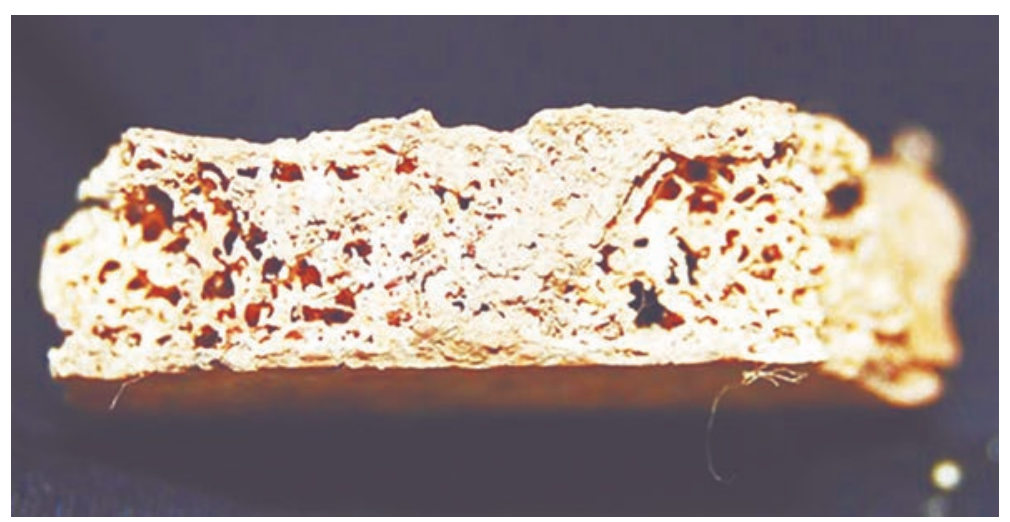

FiguRA 7. Detalle del corte en el cuerpo del esternón. Fotografía de Judith Ruiz.

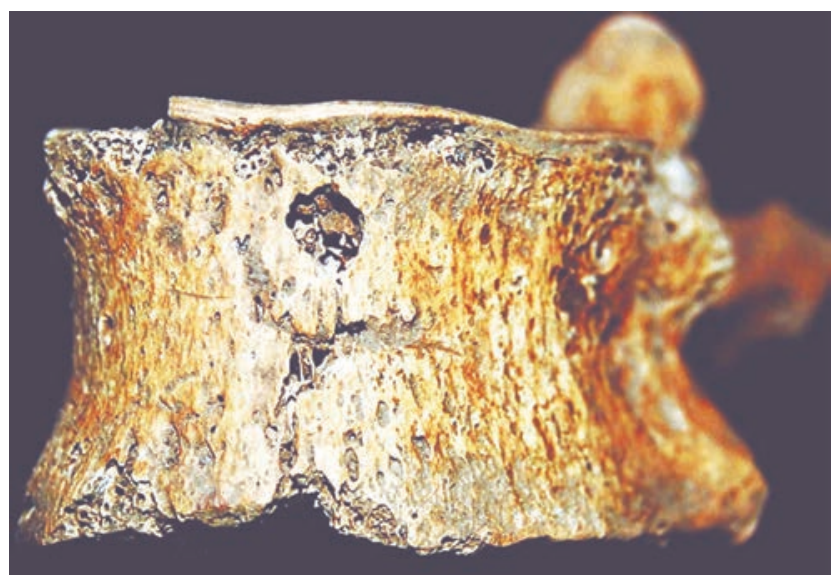

Figura 8. Huella de corte en dorsal. Fotografía de Judith Ruiz.

que la incisión se inició del lado derecho del esternón, hacia el lado izquierdo; este dato nos dice que el sacrificador estaba colocado del lado izquierdo de la víctima y la incisión se dio del lado opuesto de donde estaba ubicado. Esta técnica es similar a la reportada en un estudio sobre esternones cortados entre los mexicas de Tlatelolco, donde la mayoría de los cortes se llevaron a cabo por el lado izquierdo del sacrificado (Pijoan y Mansilla, 2004: 76, 77).

A partir de los varios procedimientos de cardiectomía documentados y propuestos hasta ahora (Robicsek y Hales, 1984: 82-87; Pijoan y Mansilla, ibid., 75-76; Tiesler y Cucina, 2007: 59; Pereira, 2010: 253-254), se propone que el acceso al corazón se realizó mediante la técnica C (Figura 9): con una incisión desde el borde derecho del esternón que continuó hasta el borde izquierdo, probablemente afectando ambas cavidades pleurales y ocasionando el colapso de los pulmones; tales reacciones pueden provocar hipoxia cerebral, que implica la pérdida de conocimiento. 


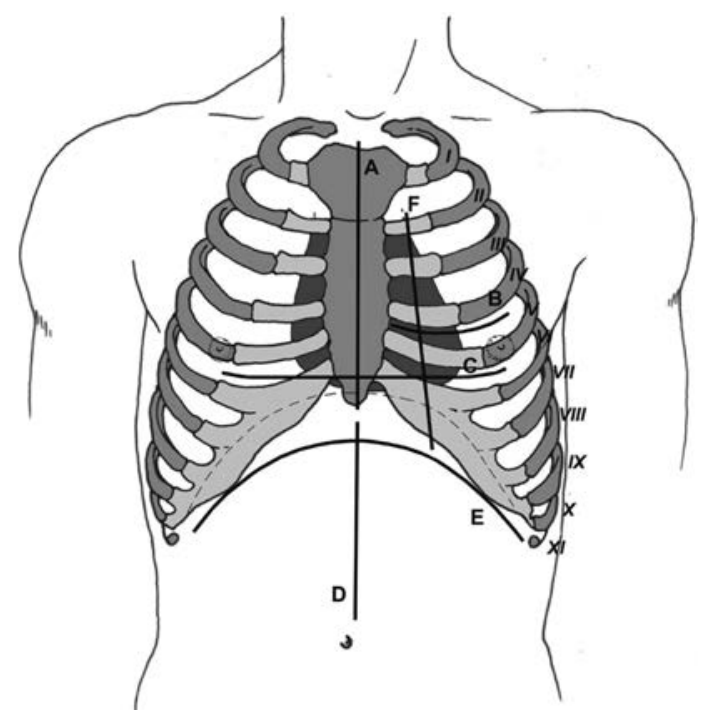

FiguRA 9. Representación gráfica de las diferentes técnicas mencionadas (Tiesler y Cucina, 2007: 59), donde se señala el corte del esternón del Entierro 1, Lagartero.

Técnica A, esternotomía axial media; Técnica B, toracotomía trasversal izquierda;

Técnica C, toracotomía bilateral transversal; Técnica $\mathrm{D}$, acceso transabdominal vertical o desde el abdomen; Técnica E, acercamiento subtorácico transdiafragmático; Técnica F, acceso paraesternal.

Cabe mencionar que la técnica C también está documentada para el área mexica entre los tlatelolcas, así lo evidencian varios esternones cortados transversalmente (Pijoan y Mansilla, ibid., 76-78). En la región maya, en tres sitios del Clásico (Calakmul, Becán y Palenque) la evidencia osteológica apunta a que el acceso al corazón se llevaba a cabo por debajo de la caja torácica (técnica E), debido a marcas de corte por impacto en la porción izquierda de las últimas vertebras dorsales (Tiesler y Cucina, 2007: 60-63; 2006: 495). En la Ofrenda 111 del Templo Mayor se empleó la técnica $\mathrm{D}$, ingresando a la cavidad torácica desde el abdomen (López Luján et al., 2010: 380); Igualmente, Pereira (2010: 253) propone que para el área de Loma Alta, Michoacán, el acceso habría sido subtorácico, por debajo de las costillas, debido a la evidencia de dos incisiones paralelas en el extremo inferior del esternón.

La presencia de marcas en diferentes áreas de la región torácica habla de las variantes del sacrificio por extracción del corazón documentadas en el área mesoamericana; no presentan necesariamente a nivel regional el mismo patrón de acceso al corazón, con posibilidad de influencia o intercambio de técnicas, pues la técnica $\mathrm{C}$ se ha encontrado en el Centro de México entre los mexicas (Pijoan y Mansilla, ibid., 77), al igual que la técnica usada con el individuo estudiado.

A pesar de la diversidad de técnicas, la abertura realizada para extraer el corazón se aprecia en representaciones escultóricas, pinturas murales, vasos polí- 
cromos, esculturas en bajo relieve y en varios códices mayas, mexicas y mixtecos (Figura 10). Destaca el hecho de que el sacrificio por extracción del corazón y la decapitación eran el principal medio para este fin. El sacrificio humano fue una práctica común entre los antiguos mayas, muy arraigado al momento del contacto con los españoles y con una pervivencia posterior (Serafin y Peraza, 2008: 232).

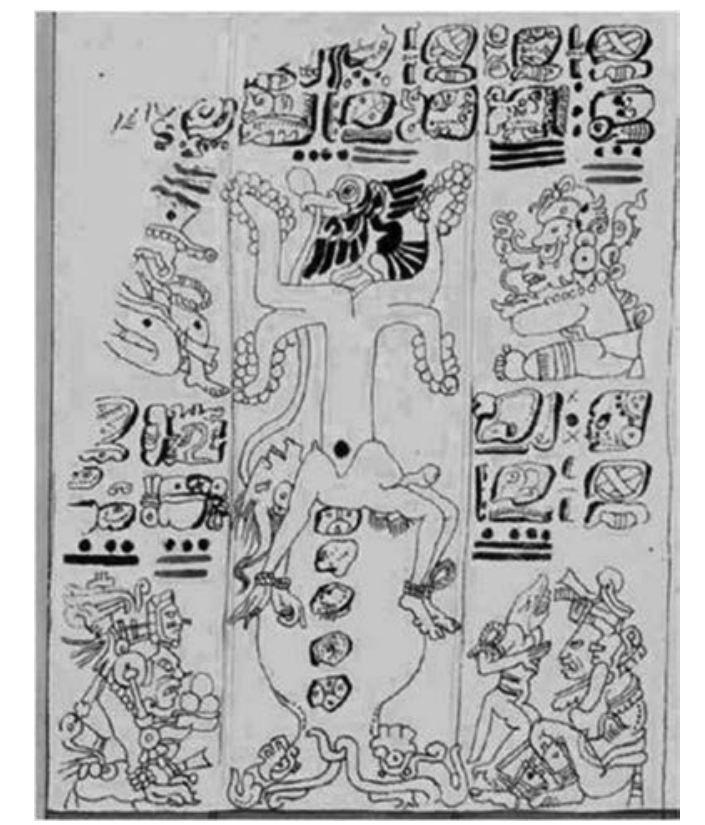

FIGURA 10. Víctima tras cardiectomía ritual; del pecho emerge el árbol cósmico de la vida. Códice Dresde, página 3.

El corazón en la cultura maya no sólo era un órgano, contenía el germen de la vida que hacía surgir el mundo, tal y como se puede apreciar en el Códice Dresde, de la península de Yucatán (página 3, figura 12): un hombre amarrado de pies y manos posado sobre una piedra sacrificial, tiene el pecho abierto y del lugar del corazón surge un árbol en cuyas ramas se posa un pájaro. El árbol simboliza el eje del mundo que surge del corazón y el cosmos entero se renueva gracias al hombre que da su corazón. En el mito de creación entre los mayas k'iche, una de las primeras deidades que fecundaron la tierra es el llamado Corazón del Cielo, donde reside el principio y germen de la existencia (Nájera, 1987: 144-145).

El sacrificio humano entre los mayas era considerado una expresión importante dentro del ámbito religioso; a través de esta conducta ritual se ofrecían las esencias vitales y alimento de los dioses (Nájera, ibid., 42, 110; Tiesler y Cucina, 2006: 505).

Son diversos los escenarios que hacen recurrente la inmolación ritual, como el designio de llevar acompañantes en las celebraciones fúnebres de algún personaje importante; en situaciones provocadas por acontecimientos imprevistos, tal es el 
caso de las sequias; la celebración de un acto relevante, como la ascensión al trono; dentro de festividades fijas de acuerdo al calendario establecido, con diversos fines y significados; en ceremonias de inicio, en la conmemoración o la consagración de una construcción, la ampliación o terminación de un templo o un ciclo temporal, por mencionar algunos (Olivier y López, 2010: 27; Matos, 2010: 46-47). ${ }^{10}$

\section{Segmentación del cuerpo}

Diversas alteraciones culturales visibles en los restos óseos humanos indican que, después de la muerte, el cuerpo de los sacrificados era manipulado con diferentes fines, según la celebración en que se realizaba la occisión ritual; sobre todo, este proceso consistía en separar, cortar y desprender partes del cadáver.

El tratamiento antropogénico es evidente a través de marcas que son identificadas como huellas de cortes, fracturas, impactos intencionales y modificaciones térmicas (Pijoan y Mansilla, 2004: 70). A grandes rasgos se mencionan cada una de ellas:

- Desarticulación/desmembramiento: Consiste en separar una o varias partes del cuerpo, con marcas en áreas periarticulares, concentrándose en regiones de inserción músculo-ligamentosas.

- Descarnamiento: Se retiran músculos y ligamentos; se pueden apreciar marcas en la superficie cefálica y del postcráneo, en diáfisis y en áreas de inserción músculo-ligamentosas.

- Desollamiento: Se retira la piel del resto del cuerpo, para después vestirla o portarla.

- Decapitación: Se separa la cabeza del resto del cuerpo, ya sea peri o post mortem; no implica necesariamente la forma de muerte.

- Cocción peri o post mortem: Es la exposición al fuego, calcinación o incineración; ya sea que se trate sólo de segmentos corporales o el cuerpo entero.

El individuo estudiado presenta varias huellas de corte, que según el área y porción del hueso se han asociado al desmembramiento; no presenta huellas de heridas punzocortantes (percusión, desgarres o fracturas).

El cuerpo fue separado en tres secciones: caja torácica, cadera y extremidades inferiores. Esto se puede inferir a partir de la posición primaria de la caja torácica, la desarticulación de los huesos de la cadera y la dispersión de las extremidades inferiores articuladas, en el contexto arqueológico. Estas tres secciones no guardaban relación anatómica.

${ }^{10}$ El sacrificio consiste en que un ser humano o animal sea consagrado para crear, mantener o restaurar una relación entre el hombre y el orden divino; siempre y cuando lo sacralizado sufra de una destrucción parcial o total en el momento mismo del rito y dentro de un espacio sagrado, diferencia principal entre una ofrenda y un sacrificio. Una vez arrebatada la vida de la víctima, el cadáver era tratado de diferentes formas, dependiendo del tipo de muerte y el fin al que estaba dedicado el sacrificio (Nájera, 1987: 205-206). Esta práctica buscaba establecer la comunión con las fuerzas sagradas a fin de reconciliar la continuidad, asegurar la vida y el bienestar de la comunidad (Tiesler y Cucina, 2010: 204). 
Además de segmentar el cuerpo en superior, medio e inferior se dividió por lado, con la desarticulación de las extremidades izquierda y derecha, tanto las superiores como las inferiores: separación de brazos de la caja torácica y de éstos, los antebrazos; la desarticulación de los muslos de la cadera y las piernas de los muslos.

La desarticulación antes mencionada es evidente por el acomodo particular en el contexto arqueológico de los segmentos corporales y por la presencia de marcas de corte dejadas en áreas de inserción músculoligamentosas. A continuación se describen algunas de las huellas de corte.

- En el tercio externo de la clavícula izquierda, específicamente en la tuberosidad del deltoides y la curvatura externa, hay huellas de corte por la separación articular del hombro con la caja torácica, en que intervienen los músculos del hombro y el deltoides.

- En las costillas izquierdas (1, 3, 6, 8, 9 y 10) las huellas de corte son apreciables en el extremo posterior y borde inferior, específicamente donde se insertan los músculos de la espalda (serrato posterior superior y serrato posterior inferior); sólo la tercera y décima presentan huellas de corte en su cara externa, donde se inserta el músculo subclavio, localizado por debajo de la clavícula. En cuanto a las costillas derechas, las huellas de corte son visibles en el ángulo posterior, extremo posterior y cara externa de la quinta, y la tercera en su cara externa, con intención de separar estos mismos músculos (Figuras 11 y 12).
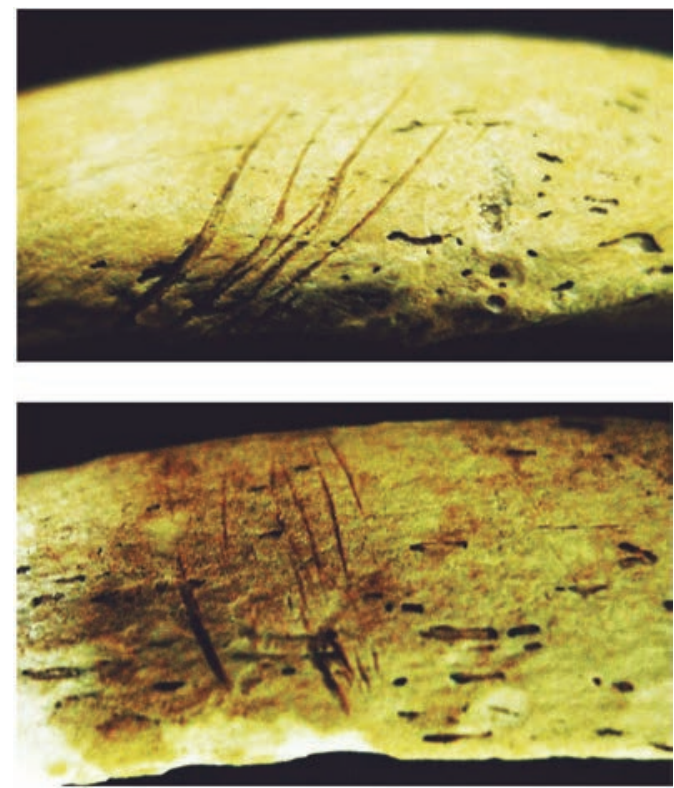

Figuras 11 y 12. Detalle de las huellas de corte en el extremo posterior de costillas izquierdas. Fotografías de Judith Ruiz. 
En la cara interna de la tibia derecha se aprecian diferentes tipos de corte. Hay marcas más superficiales en la parte proximal, mientras que en la distal son más profundas. En estas áreas se encuentran los músculos poplíteo y flexor largo de los dedos. También se encontraron marcas en el tercer metatarso, vista dorsal, donde se inserta el músculo exterior corto de los dedos.

En ambos ilíacos, tanto en su vista anterior como posterior se detectaron huellas de corte en la región del isquion, línea innominada (para cortar los músculos de la cadera o psoas, que nace de las vértebras D12 a 15; atraviesa la parte anterior de la pelvis y termina en el trocánter menor), cerca de la cresta cotiloidea y por arriba del agujero obturador. En estas zonas encontramos los músculos glúteo menor, gemelo superior, gemelo inferior y obturador interno (Figuras 13 y 14).

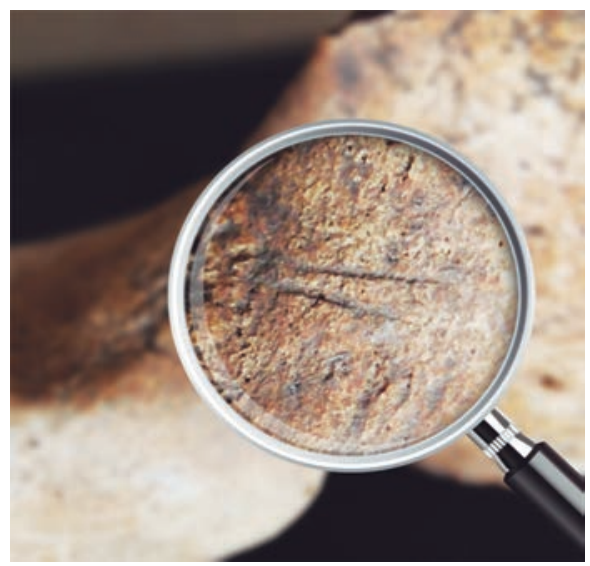

FIGURA 13. Huellas de corte en inserción del gemelo inferior, iliaco derecho. Fotografía de Judith Ruiz.

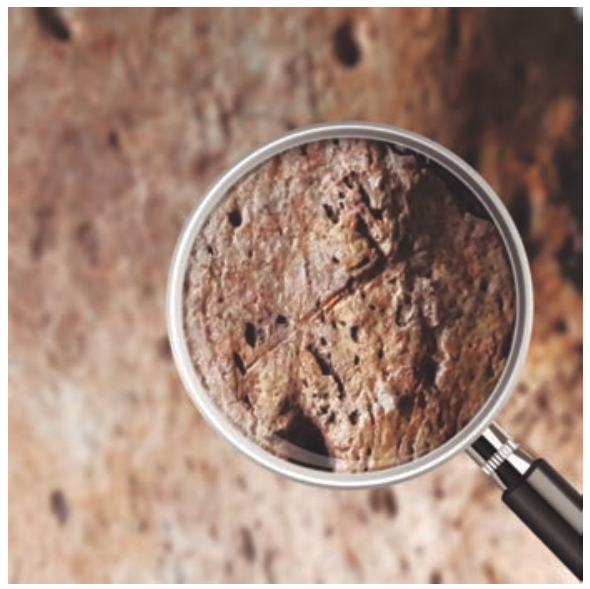

Figura 14. Huella de corte en inserción del glúteo menor, iliaco derecho. Fotografía de Judith Ruiz. 


\section{Uso ritual de segmentos corporales}

En un estudio realizado con falanges humanas localizadas dentro de incensarios procedentes de Palenque se determinó que pertenecieron tanto a personas adultas como adolescentes, las cuales presentan evidencia de huellas de impacto y/o de corte; lo que demuestra que fueron descarnados de la zona próxima a la articulación para desmembrar el dedo con mayor facilidad (Pijoan et al., 2010: 158, 160). Se resalta la importancia que tenían las manos, en especial la parte distal; reflejo de ello se observa en "el juicio de los cautivos" en el mural de Bonampak, donde por lo menos dos cautivos sangran de sus dedos porque sus falanges fueron cortadas.

En la falange I del segundo y cuarto dedo de la mano izquierda del individuo se aprecian marcas de corte; específicamente el cuarto dedo no presenta las falanges II y III, que fueron amputadas (Figuras 15 y 16).

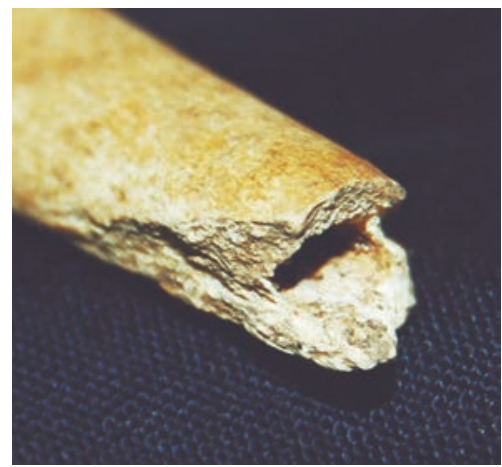

FIGURA 15. Cuarta falange proximal, incompleta de su epífisis distal. Fotografía de Judith Ruiz.

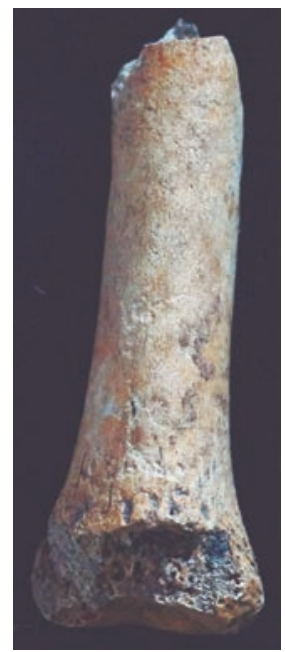

Figura 16. Corte en la epífisis proximal dejado al momento de cortar el tendón extensor del dedo. Fotografía de Judith Ruiz 
La ausencia de estas falanges, así como algunas extremidades del individuo masculino, probablemente las utilizaron en rituales. Se ha dado el caso de encontrar huesos largos entrelazados de manera alterna como un acto de sacrificio, hallados en las plataformas de Uxmal, Nohpat, Dzibilchaltun, Chichén Itzá, Tlatelolco, Tenayuca y Tula (Duncan, 2011: 552).

En el Códice Madrid se aprecian escenas de sacrificio con presencia de huesos largos cruzados en asociación con cautivos atados (Vail y Hernández, 2007 en Duncan, id.). También se tiene referencia de huesos largos en iconografía posclásica. Por ejemplo, en el juego de pelota en Chichén Itzá se representan figuras, en una procesión, con piernas de esqueleto (Salazar, 1952 en Duncan, id.).

En la Figura 17 se aprecia una escena mítica: un jaguar entrega al Dios A un contenedor con una mano derecha, probablemente un bulbo ocular y el tercio distal de un fémur; este caso ejemplifica el uso ritual de ciertos segmentos corporales en el área maya.

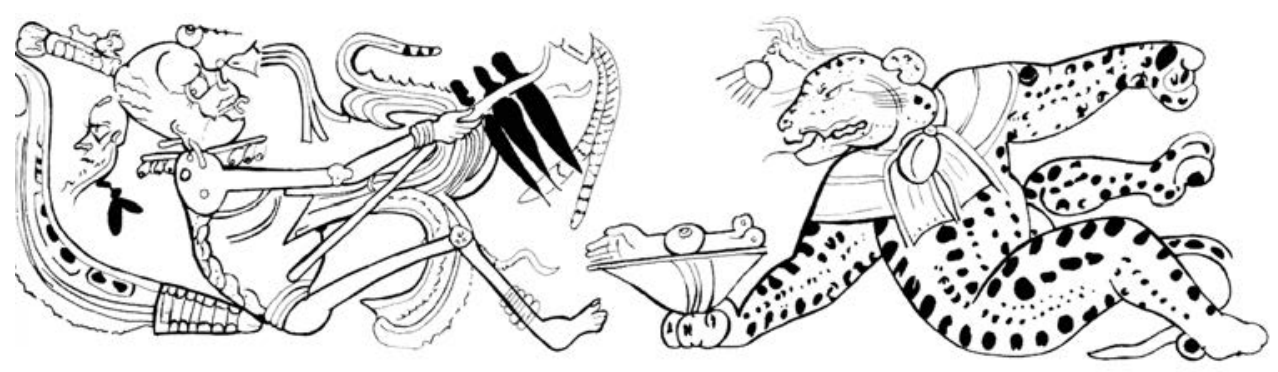

FiguRA 17. Escena mítica donde se ofrendan segmentos anatómicos humanos. Archivo Kerr 1830, trazado por M. Sánchez (Tiesler y Cucina, 2010: 207).

En el caso del presente estudio, cabe la posibilidad de que la pierna izquierda haya sido desarticulada y empleada para fines rituales, así como la parte final del cuarto dedo de la mano izquierda; o bien que se haya utilizado como materia prima.

\section{Industria del hueso humano}

Además del tratamiento corporal postsacrificial antes mencionado, pueden darse otros manejos tanto de índole ritual como con fines utilitarios, prácticos o de aprovechamiento. Tal sería el caso de la antropofagia y la disgregación de segmentos corporales, donde partes del cuerpo eran depositadas para consagrar edificaciones.

Del mismo modo encontramos la utilización de algunos segmentos corporales como reliquia y reliquias-trofeo (Urcid, 2010: 129; López Austin, 2012: 441), ya que en los huesos quedaba cierta parte de las fuerzas vitales del individuo. 
El aprovechamiento del cuerpo humano también involucra el reciclaje y manufactura, que implica el manejo de ciertos segmentos óseos para realizar instrumentos, herramientas, utensilios, artefactos y ornatos, entre otros.

$\mathrm{Al}$ encontrar dentro del registro arqueológico huesos tanto de animal como de humano modificados, con ciertas huellas reconocibles y ajenas a su topografía, es posible interpretar un proceso de manufactura para la industria, donde la materia prima se consigue del cuerpo humano y de los animales, para confeccionar diversos objetos con fines pragmáticos, rituales, decorativos y funcionales (Rojas Lugo, 2007: 71-74).

Esto implica también recurrir a la forma natural que proporcionan los huesos, dependiendo del objeto requerido; como puede ser el uso más frecuente de los huesos largos (húmeros, fémures, tibias, cúbitos y radios), que son más rectos y que presentan una superficie mayor para crear un borde de trabajo, aunque también puede darse el caso de aprovechar los huesos de la cadera, el cráneo, metatarso, falanges y hasta dientes.

El proceso de manufactura en hueso conlleva diversas etapas de trabajo; se inicia con la adquisición del segmento corporal (ya sea de humano o de animal) para obtener el hueso; le siguen las técnicas de fabricación y finalmente el uso que se le da a lo creado (Pereira, 2004: 191, 193, 196). Es posible distinguir varias marcas o huellas dejadas en los huesos que hacen alusión a estos tres procesos: huellas de corte, desgarres, perforaciones, cincelado, pulimiento, superficies desgastadas, abrasión, bruñido, grabado, patrones de reducción y pintado en hueso fresco o seco (Tiesler y Cucina, 2010: 200; Rojas Chávez et al., 2004: 91, 92).

En el registro arqueológico puede darse el caso de encontrar los productos terminados. Ejemplo de ello son las máscaras-trofeo, los omichicahuaztli o huesos estriados, punzones, tubos, bruñidores, entre otros; o bien se pueden encontrar sólo las preformas o desechos del proceso de manufactura. La literatura menciona que son los huesos de personas adultas, de ambos sexos, y no de infantes o juveniles, los predominantes para la industria humana (Rojas Chávez et al., op. cit., 89, 96).

En el individuo analizado se encontraron ciertos elementos óseos que son desecho del proceso de manufactura de objetos; estas piezas son las epífisis distales aserradas de ambos fémures, en las que se observan huellas de corte dejadas cuando se separó la diáfisis del resto del hueso, para aprovechamiento de la diáfisis, sin importar el acabado de estas partes finales (Figura 18).

También están presentes aquellas huellas dejadas cuando se separó el músculo extensor vasto intermedio del muslo, que es el que interviene en la articulación de la rodilla (porción proximal de tibia, rotula y porción distal del fémur) (Figura 19).

Tanto en imágenes de códices como en el registro osteológico se ha visto que principalmente las diáfisis de los fémures, desde la cabeza hasta el último tercio, son utilizadas para confeccionar huesos estriados y huesos decorados (Figura 20).

Por ejemplo, un estudio realizado con huesos estriados de Zacapu, Michoacán, permite aseverar que fueron empleados de la misma forma que los omichicahuaztli 


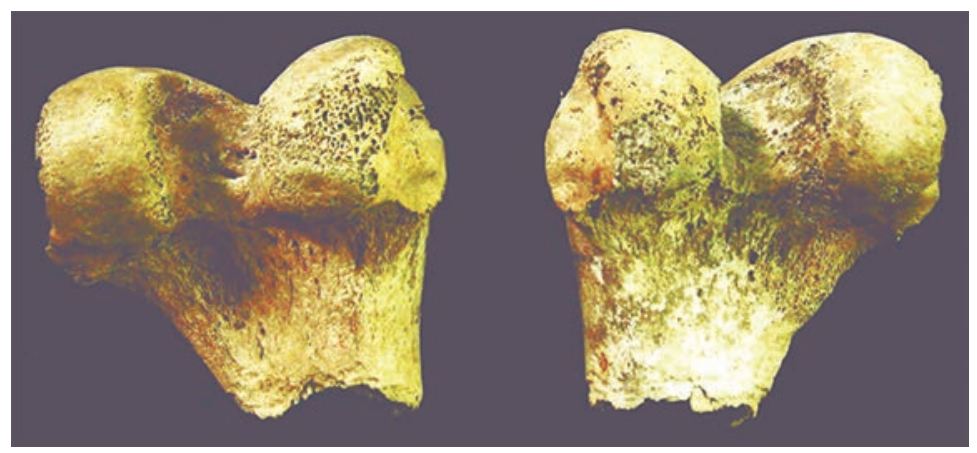

Figura 18. Epífisis aserradas de ambos fémures, vista posterior. Fotografía de Judith Ruiz.

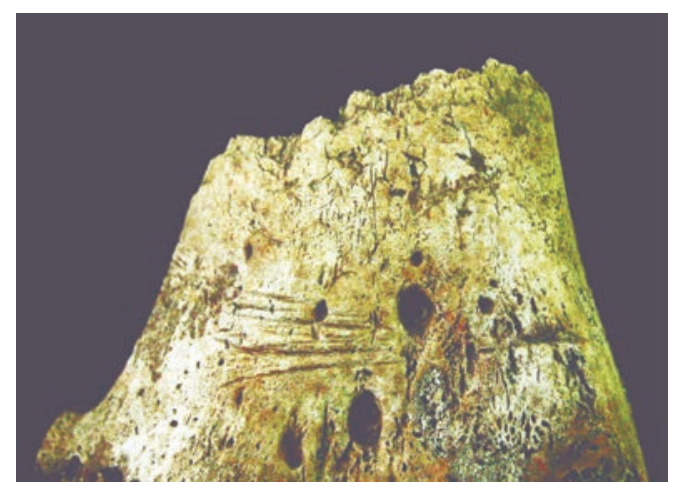

FIGURA 19. Detalle de huellas de corte, vista anterior. Fotografía de Judith Ruiz.

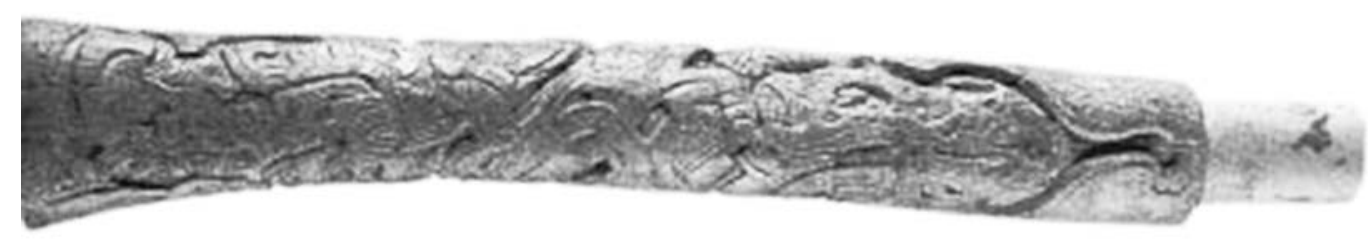

Figura 20. Fémur decorado de Chiapa de Corzo, tomado de Trejo, 2008: 23. 
o instrumentos musicales mexicas. En dicho estudio se llega a la conclusión de que los huesos usados para estos fines fueron extraídos de los cadáveres, de víctimas sacrificiales o de guerreros enemigos, muertos en batalla (Pereira, 2004: 201).

Es de resaltar que este tipo de huesos fueron muy utilizados en el Posclásico en gran parte del territorio mesoamericano, pero que aparecen desde períodos más tempranos (Pereira, id.). Según Miller (2007: 180), en el Posclásico hay testimonios del uso de huesos largos, en particular los fémures, como trofeos y/o herramientas.

En El Corzo, Teotihuacan, se documentó la presencia de desechos de diferentes segmentos anatómicos del cuerpo humano, los más representativos son vértebras y costillas; les siguen las epífisis de los huesos largos, manos y pies. Este hallazgo es significativo, ya que tales piezas son consideradas las menos funcionales por su morfología para ser utilizados en la industria ósea (Rojas Lugo, 2007: 72-75).

También es importante el hallazgo realizado en Cantona, Puebla, donde fue posible recuperar productos terminados del proceso de manufactura de herramientas y ornamentos con huellas de uso, donde se ve la preferencia por los huesos largos del esqueleto humano, correspondientes a adultos de ambos sexos (Rojas Chávez et al., 2004: 94).

\section{La fuerza del cuerpo y los rituales de consagración}

Los rituales de consagración se aplican al erigir un edificio, un templo o una casa habitación. Para llevar a cabo tales actividades se recurría al depósito de ofrendas, tanto de alimentos, como de ofrendas mágicas u ocultas, pero también la muerte de uno o varios seres sacrificados, con su posterior enterramiento bajo el edificio; este acto constituía parte integral de las ceremonias de dedicación, además de la participación de danzantes y señores de distintas jerarquías, con la finalidad de otorgar cierta fuerza vital a la edificación (Vargas y Delgado, 2007: 208-211). ${ }^{11}$

Tales sacrificios para la construcción cumplían diferentes roles: podían santificar, divinizar las edificaciones, delimitar espacios sagrados de los profanos, alejar los malos efluvios de un determinado sitio y evitar que se destruyera sin perdurar por más tiempo. Para ello, se dotaba al edificio de una fuerza sagrada permanente que protegiera a sus habitantes, a través de enterrar el cadáver de un sacrificado en los cimientos, en las paredes, o bien en las sobreposiciones ar-

${ }^{11}$ La fuerza vital proviene del ánima; una de sus funciones principales es la de animar el cuerpo; y por fuerza anímica se entiende aquellos elementos no cuantificables ni individualizables; una de sus cualidades es que dotan de vida a la persona, además de que están vinculados con las fuentes externas que les permiten regenerarse y renovarse durante los ciclos ordinarios de la vida humana (Martínez, 2007: 154). 
quitectónicas (Nájera, 1987: 43); la animicidad proveniente del sacrificado dotaba a la construcción de una fuerza vital que se reflejaba en su firmeza y resistencia. En el área maya se ha documentado que este tipo de sacrificios están asociados a la decapitación y el depósito póstumo de la cabeza de uno o varios individuos en las construcciones en general.

Por ejemplo, en la Estructura 2023 de Ixlú en el Petén, Guatemala, fueron encontrados varios cráneos colocados en pares y filas, cuatro esqueletos post craneales encima de un viejo piso y debajo de una nueva construcción; sin evidencia de objetos asociados (más que residuos ceremoniales). Tanto los cráneos como los esqueletos corresponden a individuos masculinos de un rango de edad de 15 a 36 años. Esto refleja que los individuos fueron enterrados como parte de una ofrenda dedicatoria a los episodios de construcción, con la finalidad de animar a las nuevas edificaciones (Duncan, 2011: 565).

Por lo regular las cabezas son empleadas con fines de consagración, pero puede darse el caso de que los cuerpos completos, decapitados o no, mutilados de alguna forma, o cráneos en compañía con algún segmento corporal, puedan llegar a cumplir este papel. Esta práctica se presenta desde el Preclásico Medio hasta el Posclásico (Chiapa de Corzo, Dzibilchatún, Nebaj, Chichén-Itzá, Mayapán y Santa Rita), especialmente en el Clásico Temprano (Uaxactún) y Tardío (Uaxactún, Tikal, Nebaj, Baking Pot) (Ruz, 2005: 167).

En la excavación de la estructura SE, contigua al sur del juego de pelota de Lagartero, en la parte posterior del altar, se localizaron dos muros alineados de norte a sur, y entre ellos los restos humanos. Por la ubicación y la manufactura de estos muros adosados, se colige que funcionaron como una especie de contrafuerte, ya sea preventivo o correctivo, pues el área donde se cimentaron es lacustre y el terreno llega a tener oscilaciones que producen perturbaciones en las estructuras.

Se considera que los dos muros se construyeron con el fin de brindar mayor soporte al altar, edificados posteriormente a la construcción, es decir, eran una especie de contrafuerte con fines correctivos. Sin embargo, el verdadero cimiento de los muros lo proporcionó la fuerza vital del individuo con el depósito de sus segmentos corporales; fue el vivificador, que otorgó la fuerza necesaria para que la edificación siguiera en pie; así como los huesos guardaban parte de la fuerza vital del individuo, el edificio adquiría la fuerza y durabilidad, propiciadas de manera ritual.

\section{Comentario final}

A las víctimas sacrificiales se les atribuían cargas afectivas, entidades incorpóreas dotadas de fuerzas vitales, que a través de la disgregación corporal extendían espacial y temporalmente la sacralización del acto de la inmolación.

No siempre en el sacrificio humano las víctimas eran ofrendadas de cuerpo entero; el cadáver implicaba un tratamiento diverso según los escenarios y la 
finalidad de las ceremonias, con la separación y disgregación de sus partes corporales. Este comportamiento puede relacionarse con las concepciones divisibles de la persona, es decir, la disgregación corporal no necesariamente niega su unidad o la eliminación de la víctima como residuo o desecho inanimado (Urcid, 2010: 132). Por el contrario, el tratamiento postsacrificial conlleva una transformación del cuerpo en partes manejables de manera ritual y hasta funcionales en la industria ósea humana. Este aspecto se ve plasmado en el cosmograma en la lámina 1 del Códice Tezcatlipoca del centro de México (Codex Féjérváry-Mayer, en Urcid, 2010: 132), con la división sacrificial del cuerpo humano y su distribución a los cuatro rumbos: al oriente una mano amputada, al norte el hueso descarnado de un fémur, al poniente un dorso descarnado, y al sur una cabeza decapitada.

La información expuesta y examinada en este trabajo documenta el conocimiento que se ha venido generando sobre las prácticas rituales que involucran el simbolismo del cuerpo humano en relación al sacrificio, que estuvieron presentes en el área maya, compartidas en gran medida en el ámbito mesoamericano.

\section{BIBLIOGRAFÍA}

Bass, William Marvin

1986 Human Osteology. A Laboratory and Field Manual of the Human Skeleton, 2. Columbia, Missouri: Missouri Archaeological Society, Special Public.

Buikstra Jane, Ellen y Douglas H. Ubelaker

1994 Standards for Data Collection from Human Skeletal Remains. Proceedings of a Seminar at the Field Museum of Natural History. New Jersey: Prentice Hall y Arkansas Archeological Survey Press.

Chávez Balderas, Ximena

2010 "Decapitación ritual en el Templo Mayor de Tenochtitlan: Estudio tafonómico", El sacrificio humano en la tradición religiosa mesoamericana, pp. 317-344, Leonardo López Luján y Guilhem Olivier (coords.). México: Instituto Nacional de Antropología e Historia y Universidad Nacional Autónoma de México.

Domenici, Davide

2013 "Un posible caso de sacrificio de niños del Clásico Tardío en el área zoque: la Cueva del Lazo (Chiapas)”, Estudios de Cultura Maya, XVL: 63-92.

Duncan, William Nicholas

2011 "Bioarchaeological Analysis of Sacrificial Victims from a Postclassic Maya Temple from Ixlu, El Petén, Guatemala”, Latin American Antiquity, 22 (4): 549-572.

Houston, Stephen y Andrew Scherer

2010 "La ofrenda máxima: el sacrificio humano en la parte central del área maya", El sacrificio humano en la tradición religiosa mesoamericana, pp. 169-194, Leonardo López Luján y Guilhem Olivier (coords.). México: Instituto Nacional de Antropología e Historia y Universidad Nacional Autónoma de México. 
Kaufman, Terrence

1974 Idiomas de Mesoamérica. Guatemala: José de Pineda Ibarra y Ministerio de Educación.

Krenzer, Udo

2006 Compendio de métodos antropológico forenses para la reconstrucción del perfil osteobiológico. Métodos para la determinación del sexo, t. II. Guatemala: Centro de Análisis Forenses y Ciencias Aplicadas (Serie Antropología Forense).

Lagunas Rodríguez, Zaíd y Patricia Olga Hernández Espinoza

2005 Manual de osteología. México: Escuela Nacional de Antropología e Historia.

Landa, fray Diego de

1966 Relación de las cosas de Yucatán. México: Porrúa.

López Austin, Alfredo

2012 Cuerpo humano e ideología. Las concepciones de los antiguos nahuas, vol. I. México: Universidad Nacional Autónoma de México, Instituto de Investigaciones Antropológicas.

López Luján, Leonardo, Ximena Chávez Balderas, Norma Valentín y Aurora Montúfar

2010 "Huitzilopochtli y el sacrificio de niños en el Templo Mayor de Tenochtitlan”, El sacrificio humano en la tradición religiosa mesoamericana, pp. 367-394, Leonardo López Luján y Guilhem Olivier (coord.). México: Instituto Nacional de Antropología e Historia y Universidad Nacional Autónoma de México.

López Oliva, Macarena Soledad

2013 "El ritual de la decapitación y el culto a las cabezas-trofeo en el mundo maya", tesis de Maestría en Estudios Mesoamericanos. México: Universidad Nacional Autónoma de México, Facultad de Filosofía y Letras e Instituto de Investigaciones Filológicas.

Lovejoy, Claude Owen, Richard S. Meindl, T. R. Pryzbeck y Robert P. Mensforth

1985 "Chronological Metamorphosis of the Auricular Surface of the Ilium. A New Method for the Determination of Adult Skeletal Age at Death", American Journal of Physical Anthropology, 68 (1):15-28.

Martínez González, Roberto

2007 "Las entidades anímicas en el pensamiento maya", Estudios de Cultura Maya, XXX: 153-174.

Matos Moctezuma, Eduardo

2010 "La muerte del hombre por el hombre: el sacrificio humano", El sacrificio humano en la tradición religiosa mesoamericana, pp. 43-64, Leonardo López Luján y Guilhem Olivier (coords.). México: Instituto Nacional de Antropología e Historia y Universidad Nacional Autónoma de México.

Meindl, Richard S. y Claude Owen Lovejoy

1989 "Age Changes in the Pelvis: Implications for Paleodemography", Age Markers 
in the Human Skeleton, pp. 137-168, Iscan Yasar (ed.). Springfield, Illinois: Charles C. Thomas Publisher.

Meza Peñaloza, Abigail

2015 Afinidades biológicas y contextos culturales en los antiguos teotihuacanos. México: Universidad Nacional Autónoma de México, Instituto de Investigaciones Antropológicas.

Miller, Virginia

2007 "Skeletons, Skulls and Bones in the Art of Chichen Itza", New Perspectives on Human Sacrifice and Ritual Body Treatments in Ancient Maya Society, pp.165189, Vera Tiesler y Andrea Cucina (eds.). New York: Springer.

Nájera Coronado, Martha Ilia

1987 El don de la sangre en el equilibrio cósmico. El sacrificio y el autosacrificio sangriento entre los antiguos mayas. México: Universidad Nacional Autónoma de México.

Olivier, Guilhem y Leonardo López Luján

2010 "El sacrificio humano en Mesoamérica: ayer, hoy y mañana”, El sacrificio humano en la tradición religiosa mesoamericana, pp. 19-42, Leonardo López Luján y Guilhem Olivier (coords.). México: Instituto Nacional de Antropología e Historia y Universidad Nacional Autónoma de México.

Pereira, Grégory

2004 "Estudio tafonómico de los huesos humanos estriados procedentes de Zacapu, Michoacán”, Perspectiva tafonómica, pp. 185-206, Carmen María Pijoan Aguadé y Xabier Lizarraga Cruchaga (eds.). México: Instituto Nacional de Antropología e Historia (Colección Científica).

2010 "El sacrificio humano en el Michoacán antiguo", El sacrificio humano en la tradición religiosa mesoamericana, pp. 247-274, Leonardo López Luján y Guilhem Olivier (coords.). México: Instituto Nacional de Antropología e Historia y Universidad Nacional Autónoma de México.

Phenice, Terrell Wayne

1969 "A Newly Developed Visual Method of Sexing the os Pubis", American Journal of Physical Anthropology, 30: 297-301.

Pijoan Aguadé, Carmen María y Josefina Mansilla

2004 "Esternones cortados. ¿Evidencia de sacrificio humano por extracción del corazón?”, Perspectiva tafonómica, pp. 69-86, Carmen María Pijoan Aguadé y Xabier Lizarraga Cruchaga (eds.). México: Instituto Nacional de Antropología e Historia (Colección Científica).

Pijoan Aguadé, Carmen María, Inmaculada Alemán, Josefina Mansilla y Martha Cuevas García

2010 "Los dedos como elementos de ritual en Palenque", Perspectiva tafonómica II. Nuevos trabajos en torno a poblaciones mexicanas desaparecidas, pp. 147- 
164, Carmen María Pijoan Aguadé, Xabier Lizarraga Cruchaga y Gerardo Valenzuela J. (eds.). México: Instituto Nacional de Antropología e Historia (Colección Científica).

Rivero Torres, Sonia

2007 "El sitio arqueológico de Lagartero, Chiapas", Liminar, Estudios Sociales y Humanísticos, V (1): 183-194.

Robicsek, Francis y Donald Hales

1984 "Maya Heart Sacrifice: Cultural Perspective and Surgical Technique", Ritual Human Sacrifice in Mesoamerica, pp. 49-90, Elizabeth H. Boone (ed.). Washington, D.C.: Dumbarton Oaks.

Rojas Chávez, Juan Martín, Jorge Arturo Talavera González, Enrique García García y Equipo de Bioarqueología

2004 "Una propuesta para el análisis tecnológico, morfológico y funcional de la industria de hueso humano en México", Perspectiva tafonómica, pp. 87-108, Carmen María Pijoan Aguadé y Xabier Lizarraga Cruchaga (eds.). México: Instituto Nacional de Antropología e Historia (Colección Científica).

Rojas Lugo, Raúl

2007 "Análisis del material óseo prehispánico proveniente del Corzo, Teotihuacan. Un caso de aprovechamiento del cuerpo humano", tesis de Licenciatura en Antropología Física. México: Escuela Nacional de Antropología e Historia.

Romano Pacheco, Arturo

1974 "Sistema de enterramientos", Antropología física. Época Prehispánica, 3, pp. 83112. México: Instituto Nacional de Antropología Historia.

Ruz, Alberto

2005 Costumbres funerarias de los antiguos mayas. México: Fondo de Cultura Económica.

Sahagún, fray Bernardino de

1969 Historia general de las cosas de Nueva España. México: Porrúa.

Serafin, Stanley y Carlos Peraza Lope

2007 "Human Sacrificial Rites among the Maya of Mayapán: A Bioarchaelogical Perspective", New Perspectives on Human Sacrifice and Ritual Body Treatments in Ancient Maya Society, pp. 232-250, Vera Tiesler y Andrea Cucina (eds.). New York: Springer.

Tiesler, Vera y Andrea Cucina

2006 "Procedures in Human Heart Extraction and Ritual Meaning", Latin American Antiquity, 17 (4): 493-510.

2007 "El sacrificio humano por extracción de corazón. Una evaluación osteotafonómica de violencia ritual entre los mayas del Clásico", Estudios de Cultura Maya, XXX: 57-78. 
2010 "Sacrificio, tratamiento y ofrenda del cuerpo humano entre los mayas peninsulares", El sacrificio humano en la tradición religiosa mesoamericana, pp. 195226, Leonardo López Luján y Guilhem Olivier (coords.). México: Instituto Nacional de Antropología e Historia y Universidad Nacional Autónoma de México.

Trejo Mojica, Juana Amalia

2008 "Los restos óseos humanos como objetos ideológicos del período Clásico maya”, Dimensión Antropológica, 42: 7-31.

Ubelaker, Douglas

1989 "The Estimation of Age at Death from Immature Human Bone", Age Markers in the Human Skeleton, pp. 55-70. Springfield, Illinois: Charles C. Thomas.

Urcid, Javier

2010 "El sacrificio humano en el suroeste de Mesoamérica", El sacrificio humano en la tradición religiosa mesoamericana, pp. 115-168, Leonardo López Luján y Guilhem Olivier (coords.). México: Instituto Nacional de Antropología e Historia y Universidad Nacional Autónoma de México.

Vargas Pacheco, Ernesto y Angélica Delgado Salgado

2007 "Las grandes remodelaciones en El Tigre, Campeche. Contextos rituales de inicio y/o terminación", El patrimonio arqueológico maya en Campeche, pp. 207234, Ernesto Vargas y Antonio Benavides (eds.). México: Universidad Nacional Autónoma de México, Instituto de Investigaciones Filológicas, Centro de Estudios Mayas (Cuadernos del Centro de Estudios Mayas, 35).

Velázquez García, Erik

2011 "Las entidades y las fuerzas anímicas en la cosmovisión maya clásica”, Los mayas, voces de piedra, pp. 235-254, Alejandra Martínez de Velasco y María Elena Vega (coords.). México: Ámbar Diseño. 